\title{
"Viver em paz no campo é coisa do passado": deslocamento espacial de ações criminosas e a ressignificação do rural brasileiro
}

\author{
"Living in the countryside is a thing of the past": spatial displacement \\ of criminal acts and resignification of the Brazilian rural
}

\section{João Paulo Louzada Vieira ${ }^{1}$ Sheila Maria Doula ${ }^{2}$}

\footnotetext{
1 Mestre em Extensão Rural pela Universidade Federal de Viçosa, Especialista em Direito Urbanístico e Ambiental pela Pontifícia Universidade Católica de Minas Gerais, Bacharel em Direito pela União de Ensino Superior de Viçosa e Licenciado em História pela Universidade Federal de Viçosa. Bolsista do CNPQ, Brasil.

E-mail: joaopaulo.direito@yahoo.com.br http://lattes.cnpq.br/7510121999206103 iD http://orcid.org/0000-0002-9931-7248

1 Doutora em Antropologia Social pela Universidade de São Paulo e Pós-doutora pelo Programa Postdoctoral de Investigación en Ciencias Sociales, Niñez y Juventud da CLACSO. Professora Associada do Programa de Pós-graduação em Extensão Rural, Departamento de Economia Rural, Universidade Federal de Viçosa. Bolsista do CNPQ, Brasil.

E-mail: sheiladoula@gmail.com 19 http://lattes.cnpq.br/7494420896589436 iD http://orcid.org/0000-0003-0310-9055
}

RESUMO: O aumento da criminalidade no Brasil vem se destacando gradativamente nos veículos de comunicação e sendo debatido pelos órgãos governamentais e secretarias de Segurança Pública. Essa expansão da criminalidade, além dos contextos urbanos, também passa a ser observada no campo. Neste sentido, o presente artigo tem por objetivo analisar as representações sociais da mídia sobre o deslocamento da criminalidade para os espaços rurais. Metodologicamente, optou-se por analisar matérias veiculadas nos principais telejornais brasileiros no período de janeiro de 2017 a março de 2018.Os resultados da pesquisa indicam que o imaginário que se tinha sobre o campo se modifica e hoje esse espaço passa a ser ressignificado pela insegurança e pelo medo. Assim, a criminalidade e violência vêm expandindo suas fronteiras e chegando ao campo, onde passa a ser incorporada nas estatísticas de segurança pública nacional. Palavras-chave: Criminalidade. Campo. Representações sociais. Mídia. Segurança pública.

\begin{abstract}
The increase of criminality in Brazil has been gradually highlighted in the media and debated by the government and Departments of Public Security. This expansion on criminality go beyond the urban context and is also verified in the countryside. Therefore, this work analyzes the social representations on the media over the displacement of criminality to rural spaces. The methodology of this research consists of the analysis of stories broadcasted on the main Brazilian TV news between January 2017 and March 2018. Results showed that the imaginary we had of the countryside is changing and nowadays this space got re-signified by lack of security and fear. So the crime rate and violence increases getting the countryside and reaches the statistics of National public security.

Keywords: Criminality. Countryside. Social representations. Media. Public security.
\end{abstract}

\section{Introdução}

O índice de criminalidade no Brasil tem se elevado gradativamente nos últimos anos, impondo-se na agenda política das ações go- vernamentais e como pauta cotidiana dos veículos de comunicação. De acordo com dados divulgados pelo Anuário Brasileiro de Segurança Pública, em sua $11^{a}$ edição publicada no dia 30 de outubro de 2017, o país registrou o 
maior número de homicídios da história no ano de 2016, contabilizando um total de 61. 619 mortes violentas. Tal número equivale a 168 mortes por dia, sete assassinatos por hora, totalizando um aumento de 3,8 \% em relação ao ano de 2015. O Brasil ocupa atualmente o sétimo lugar no ranking dos países mais violentos do mundo e devido à fragilidade do Sistema Nacional de Segurança Pública, o gasto orçamentário destinado a este setor nas ações governamentais vem se equiparando ou até mesmo ultrapassando áreas importantes de gestão pública como a educação, saúde e infraestrutura (DINIZ, 2005).

Diariamente várias ocorrências são contabilizadas pelas agências policiais, envolvendo uma diversidade de crimes praticados no território nacional e cada região se destaca com um tipo específico de ocorrência, pois a tipificação criminal possui definições e categorias distintas. Neste estudo são analisadas duas categorias: crimes contra a pessoa (crimes denominados violentos) e crimes contra o patrimônio (que envolvem a propriedade e os bens materiais). Dentro da categoria de crimes contra o patrimônio temos: furto, roubo, extorsão, extorsão mediante sequestro, estelionato, dano e outros. Já na primeira se configuram aqueles que atentam contra a vida do ser humano, como homicídio tentado e consumado, lesões corporais, estrupo, entre outros (FELIX, 2002). Por envolver diversas categorias, o conceito de crime não apresenta uma definição satisfatória para o ordenamento jurídico brasileiro, sendo possível estabelecer apenas alguns parâmetros nos quais o indivíduo atente contra a ordem pública/privada e a legislação brasileira.

Ultrapassando as fronteiras das cidades, verifica-se que atualmente a criminalidade se desloca para o campo, onde novos alvos aparecem no protagonismo e favoritismo de ações criminosas. Neste sentido, pretende-se neste artigo analisar se o aumento da criminalidade no campo e sua veiculação pelas mídias influenciam na modificação das representações sociais sobre o rural brasileiro.

\section{Panorama geral da criminalidade no campo segundo os dados da Confederação da Agricultura e Pecuária do Brasil - CNA}

Várias ações têm sido planejadas por órgãos e entidades governamentais, sindicatos de produtores rurais, empresas de segurança privada, entre outros, objetivando minimizar a intensificação da criminalidade no campo. Dentre as propostas citam-se a criação de delegacias especializadas em crimes rurais, o aprimoramento de mecanismos de segurança no campo, a utilização de patrulhas rurais e um Projeto de Lei que discute o porte de armas para produtor rural. Para conhecer melhora situação, a Confederação da Agricultura e Pecuária do Brasil (CNA) criou o Observatório da Criminalidade no Campo que busca investigar e realizar um mapeamento e apresentar possíveis soluções para combater o crime e a violência que atinge o meio rural (CNA, 2017).

Dentre as principais ações do Observatório da Criminalidade no Campo está a criação de um formulário no site da Confederação da Agricultura e Pecuária do Brasil ${ }^{1}$ pelo qual produtores rurais de qualquer região brasileira podem relatar casos de violência. Após a realização do procedimento de cadastro e de relato da ação criminosa, o formulário é enviado e analisado pelos integrantes do Observatório para um mapeamento das regiões mais afetadas e dos principais crimes cometidos. Esse mapeamento é uma iniciativa que contribui para os estudos sobre a criminalidade no campo, uma vez que há uma grande lacuna de trabalhos científicos sobre as modificações recentes dos crimes, as demandas por políticas públicas e iniciativas privadas de segurança, os

\footnotetext{
${ }^{1}$ https://www.cnabrasil.org.br/projetos-e-programas/ob servat\%C3\%B3rio-da-criminalidade-no-campo

https://periodicos.unifap.br/index.php/estacao Macapá, v. 9, n. 1, p. 133-146, Jan./Mar. 2019
} 
impactos do aumento da criminalidade nos diferentes segmentos sociais rurais e sobre como o deslocamento espacial da criminalidade afeta as representações sobre o rural.

O Observatório da Criminalidade no Campo contabilizou e divulgou em vários veículos de comunicação resultados do levantamento sobre os relatos de crimes no ano de 2017 (Figura 1). Somente nesse ano - 2017 - foram contabilizadas 149 ocorrências no período de janeiro a julho, dos quais $78 \%$ das vítimas registraram Boletim de Ocorrência em delegacias, enquanto $21 \%$ optaram por não realizar o procedimento. Destaca-se ainda que há uma alta reincidência dos crimes, contabilizando um total de $66 \%$ dos casos analisados (CNA, 2017). ${ }^{2}$

Figura 1 - Tipos de ocorrências criminais no campo Figure 1 - Types of criminal occurrences in the countryside

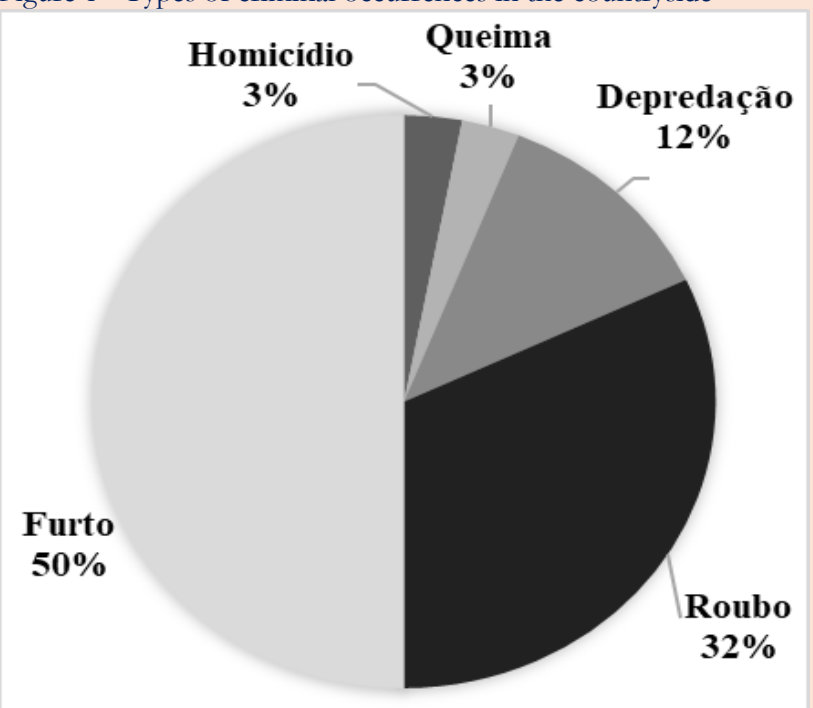

Fonte: Observatório da Criminalidade no Campo (CNA) $-2017 .^{3}$

2 É importante esclarecer que esses dados não permitem uma aferição completa da situação, pois a Confederação da Agricultura e Pecuária do Brasil (CNA) contabiliza apenas os relatos espontâneos enviados por formulário e principalmente pelo fato de os proprietários rurais não registrarem Boletim de Ocorrência nas delegacias, localizadas nas cidades, o que em algumas regiões do país, pode representar horas de viagem.

3 Os Dados e gráficos foram enviados pelo CNA por email com autorização para seu uso.
Conforme destacado pelo Observatório da Criminalidade no Campo, entre os itens de maior incidência de furto estão os animais, contabilizando 53\%, seguido pelos equipamentos agrícolas $(29 \%)$ e dos bens particulares com um total de 18\% na escala nacional. Segundo os dados, os pecuaristas aparecem como principal alvo da ação criminosa, tendo seus animais furtados paulatinamente de suas propriedades (CNA, 2017).

Em um panorama nacional da criminalidade no campo, os Estados que concentraram maiores índices de ocorrências foram Minas Gerais (29\%), seguido pela Bahia (17\%), sendo que o somatório de ocorrências nessas duas Unidades da Federação contabilizou quase a metade dos casos brasileiros (CNA, 2017).Tal característica pode ser justificada por serem estas, as Unidades da Federação com maior número de propriedades rurais. No caso específico de Minas Gerais, soma-se a isso, o grande número de Municípios de pequeno porte e as possibilidades de fuga.

Ainda em fase de aprovação, o polêmico Projeto de Lei 224/2017, proposto pelo Senador Wilder Morais (Partido Progressista GO), bem como Projeto de Lei 6717/2016, proposto pelo Deputado Afonso Hamm (Partido Progressista - RS), buscam a permissão do porte de arma de fogo para proprietários e trabalhadores residentes em áreas rurais, maiores de 25 anos de idade, como meio de defesa pessoal, patrimonial e familiar. Para o requerimento do porte rural de arma de fogo deverão ser cumpridos alguns requisitos tipificados pela Lei, como a apresentação de comprovante de residência em área rural, documentação de identificação pessoal e atestado de bons antecedentes. A validade da licença do porte rural de arma de fogo terá um período máximo de duração de dez anos, sendo limitada ao espaço da propriedade rural.

$\mathrm{Na}$ justificativa da proposição do Projeto de Lei, o Deputado Afonso Hamm argumenta que a demora na sua aprovação poderá acarre- 
tar prejuízos ao produtor rural, uma vez que ele, sua família e propriedade ficarão desprotegidos. O PL 6717/2016, desde o ano de 20164 encontra-se aguardando parecer do relator na Comissão de Segurança Pública e Combate ao Crime Organizado (CSPCCO).

Uma das críticas dirigidas ao Projeto de Lei6717/2016é que o Governo, ao invés de investir em políticas para aquisição e disponibilização de equipamentos de segurança visando a proteção dos produtores rurais, principalmente aqueles que possuem baixa renda, opta por armar a população para que esta entre em um confronto direto com o criminoso, realizando o trabalho das autoridades de segurança pública e policiais. Não obstante, cabe expor que tais ações propostas pelos Deputados vêm de encontro a Constituição Federal de 1988 ferindo o dever do estado em garantir segurança pública à população. Para além, ressaltasse a pouca ou quase nenhuma estrutura disponível para que os órgãos policiais possam, de fato, desenvolver ações efetivas no meio rural.

Além dessa iniciativa, diversos outros mecanismos de defesa têm sido desenvolvidos com objetivo de aumentar a segurança e diminuir a criminalidade no campo. Entre eles destacam-se a Cartilha de Orientação para Prevenção da Criminalidade no Meio Rural elaborada pela Federação da Agricultura e Pecuária do Estado de Minas Gerais e pelo Serviço Nacional de Aprendizagem Rural (FAEMG/SENAR-MG), instalação de câmeras em estradas vicinais com reconhecimento facial, instalação de alarmes e sistemas de geoprocessamento nas propriedades, implementação de sirenes que alcançam longas distâncias para chamar atenção da vizinhança, treinamento de cães, cadastro da propriedade junto à polícia, entre outros.

Para Beato (1998), antes da execução da ação criminosa, o infrator realiza um mapea-

\footnotetext{
${ }^{4}$ Ainda em 2019 o referido PL continua aguardando o parecer do relator.
}

mento dos possíveis locais que serão alvos da prática delituosa, o que acaba influenciando sua tomada de decisão. Neste sentido, o campo vem sendo considerado um ambiente em expansão para determinados crimes pelas condições que apresenta, ou seja, marcado por uma ampla espacialidade e baixo nível de segurança.

É importante destacar que nos últimos anos os estudos dedicados à criminalidade no campo realizam uma abordagem diferente do viés desta pesquisa, pois analisam a violência gerada pelos conflitos agrários e/ou socioambientais no país. Embora haja a presença de criminalidade em muitos desses conflitos (como assassinato de lideranças trabalhadoras, sindicalistas e ambientalistas), a proposta desta pesquisa é observar a criminalidade que até décadas atrás era restrita aos centros urbanos, mas que agora se expande para o campo caracterizando-se como uma violência não tipicamente agrária (de luta pela terra e defesa de recursos naturais) que se convencionou chamar de "violência do campo".

Diante da dimensão do problema, da sua visibilidade nos veículos de comunicação e da grande lacuna de pesquisas científicas sobre o tema, o presente artigo tem por objetivo analisar como a mídia representa o avanço da criminalidade no campo. Pretende-se observar através dos discursos de diferentes atores sociais (produtores rurais, residentes no campo, repórteres e instituições)se o aumento da criminalidade é causa/consequência de uma nova escala valorativa sobre o mundo rural. Para alcançar o objetivo, optou-se por analisar notícias veiculadas por duas emissoras de televisão com alto índice de audiência nacional, a Rede Globo de Televisão e o Grupo Bandeirantes de Comunicação.

\section{Metodologia}

Para este estudo, a técnica de coleta de dados consistiu em mapear as notícias divulga- 
das pela mídia televisiva sobre a criminalidade no campo. A partir da década de 1980 a violência no campo passou a ganhar notoriedade pelos programas televisivos devido ao grande número de "massacres" que ocorreram em áreas rurais de todo o país, principalmente na região norte do Brasil. Nos últimos anos, principalmente a partir do ano de 2010, começa a ser televisionado com maior frequência crimes contra o patrimônio em áreas rurais.

Isto posto, tomaremos para fins de análise o período de janeiro de 2017 a março de 2018, período este em que houve uma intensificação de matérias jornalísticas e dos debates públicos. Também nesse período o Observatório da Criminalidade no Campo passou a realizar o registro dos crimes ocorridos no meio rural em função do grande número de relatos enviados à eles.

As reportagens analisadas foram produzidas e veiculadas pelas emissoras Rede Globo de Televisão e Grupo Bandeirantes de Comunicação, sendo reproduzidas a nível local e nacional por diversos programas de televisão com públicos variados e horários de exibição distintos 5 .

A pesquisa tem um caráter exploratório, com utilização de fontes bibliográficas e documentais, para as quais utilizou-se a análise de conteúdo e análise do discurso para examinar as representações sociais contidas nas falas

\footnotetext{
${ }^{5}$ A Rede Globo de Televisão iniciou seu trabalho televisivo no ano de 1957. Anteriormente transmitia apenas programas de rádio (Rádio Globo). No ano de 1965 foi oficialmente inaugurada a TV Globo com sede localizada na cidade do Rio de Janeiro. Atualmente a TV Globo conta com diversas filiais espalhadas pelo país, sendo umas das principais redes de televisão com maior índice de audiência no Brasil e no Mundo (GLOBO, 2013).Já o Grupo Bandeirantes foi criado em 1937 a partir da Rádio Bandeirantes. Iniciou sua trajetória de TV no ano de 1967 na cidade de São Paulo, onde está localizada sua sede. Atualmente conta com mais de 40 empresas integradas em diversas formas de comunicação, sendo um dos principais canais da TV aberta brasileira (GRUPO BANDEIRANTES, 2017).
}

dos diferentes atores sociais (RAUPP; BAUREN, 2003; GIL, 2008; BARDIN, 2011).

Foram analisados40 vídeos jornalísticos disponíveis nas plataformas digitais das referidas emissoras. Posteriormente buscou-se realizar o tratamento dos conteúdos dos vídeos através das imagens, discursos e argumentos apresentados pelos diversos entrevistados, buscando interpretar as informações com a teoria das representações sociais.

\section{Representações sociais e mídias}

O conceito de "representações coletivas" foi criado e difundido a partir da sociologia durkheimiana e passou a adquirir maior importância nos últimos anos, principalmente no campo das ciências humanas, quando foi reelaborado por Serge Moscovici em 1961. Atualmente a teoria das "representações sociais" é utilizada em diversos campos científicos, pois permite analisar as formas, os conteúdos e as transformações nos processos de conhecimento (SÊEGA, 2000).

Representações Sociais são "maneiras de interpretar e pensar a realidade cotidiana, uma forma de conhecimento da atividade mental desenvolvida pelos indivíduos e por grupos para fixar posições em relação a situações, eventos, objetos e comunicações que lhe concernem" (SÊGA,2000, p. 1). Assim, toda representação social busca representar determinado objeto ou alguém, sendo estabelecida como um processo que visa determinar uma relação entre o mundo e as coisas (SÊGA, 2000).

Dentro do campo das representações, destaca-se a importância que o imaginário possui numa sociedade, sendo ele manifestado por meio de imagens e discursos que expressam a realidade interior de um grupo social (PESAVENTO, 1995). É importante destacar que as representações sociais não são estáticas, ou seja, elas podem se modificar com as transformações da própria sociedade, sendo esta- 
belecidas como "produtos e processos de uma atividade de apropriação da realidade exterior ao pensamento e de elaboração psicológica e social dessa realidade" (JODELET, 2001, p.22). Neste sentido, a teoria das representações sociais se torna apropriada para analisar os deslocamentos da criminalidade entre espaços urbanos e rurais e, ao mesmo tempo, as modificações simbólicas que são processadas e postas em circulação pela mídia em face de uma nova realidade.

Os veículos de comunicação de massa ainda desempenham um grande papel na sociedade contemporânea brasileira. Atuam na difusão do conhecimento, ou seja, caracterizamse como um elo entre as representações do mundo exterior que se relacionam com o conhecimento pessoal do indivíduo, através de sua bagagem cultural. Neste sentido, a mídia torna-se um ponto de referência significativo na formação e disseminação de representações sociais (FERNANDES, 2001). Na sociedade democrática contemporânea, ela é considerada um dos principais meios produtores de representações sociais, e independente de seu conteúdo (falso ou verdadeiro), exerce o papel de formar opiniões e orientar a conduta dos atores sociais (PORTO, 2009).

A televisão permanece ainda como um dos principais meios de acesso à informação no Brasil, principalmente para a população mais pobre, rural ou urbana. Além disso, a TV apresenta uma linguagem mais acessível e o recurso das imagens facilita a fixação da mensagem (FERNANDES, 2001).

As imagens e os discursos divulgados pela mídia constituem uma parte da construção social da realidade e, por suas características comunicacionais específicas, as mídias constroem e veiculam eventos sociais extraordinários e provocam uma reorientação nas formas de pensar sobre as situações que estão em foco e que indicam transformações na sociedade (PESAVENTO, 1995; SILVA; DOULA,2014). O potencial de dramatização em- pregado nas imagens para representar essa realidade pode ser mais facilmente assimilado pelo receptor do que somente o discurso; assim os mapas, fotos, filmagens in loco e os esquemas gráficos estimulam com mais eficácia os aspectos cognitivos e emotivos dos telespectadores, principalmente quando envolve um assunto tão impactante como violência e criminalidade (MOIRAND,1997 apud MENASCHE 2005).

Dessa forma, a utilização da teoria das representações sociais nesse artigo pretende colaborar com o entendimento sobre a criminalidade no campo através de uma perspectiva de análise que deriva das mensagens e propagações informativas veiculadas pela mídia para seu público alvo, principalmente os atores sociais ligados ao campo.

\section{Resultados e discussões}

Os espaços rurais, até bem pouco tempo, exerciam grande atração sobre a população citadina, pois eram representados como locais de bem estar, descanso, lazer, tranquilidade e opostos aos centros urbanos que apresentavam um alto índice de criminalidade e violência, poluição sonora, visual e atmosférica. A negatividade do urbano e a positividade do rural haviam se tornado processos simbólicos convergentes:
A valorização da localidade de origem em opo- sição à cidade grande tem como principal parâ- metro a violência que vem assustadoramente tomando conta do cenário das grandes cidades brasileiras. Assim, o que antes era considerado negativo - "lugar parado", "onde nada ocorre" - atualmente tornou-se sinônimo de "tranquilida- de", segurança e "boa qualidade de vida" (CARNEIRO, 2007, p. 64).

No entanto, conforme vem sendo destacado pela mídia, principalmente pelos programas vinculados às atividades agrícolas, o desenvolvimento econômico trouxe significativas mudanças para o campo. A criação de

https://periodicos.unifap.br/index.php/estacao Macapá, v. 9, n. 1, p. 133-146, Jan./Mar. 2019 
diversas políticas públicas para o setor agrícola, bem como a utilização de instrumentos tecnológicos sofisticados na agricultura, colaboraram com o aumento da produtividade e rentabilidade desse setor econômico e na facilitação mercadológica de seus produtos. O agronegócio, divulgado nas propagandas televisivas como um setor de riqueza rural, vem sendo representado como atrativo para interesses citadinos como, por exemplo, implementação de indústrias e realização de grandes transações monetárias nos espaços rurais. Segundo as narrativas da mídia, as transformações econômicas ocorridas nos pequenos e médios municípios brasileiros, o baixo nível de segurança pública local e a facilidade de evasão por estradas vicinais ou pistas de pouso clandestinas são fatores apontados para um aumento da criminalidade e violência no espaço rural. Assim, a criminalidade, que há poucas décadas era vista como fenômeno tipicamente urbano, passa a ser considerada como problema social também no meio rural, colocando em xeque as representações positivas sobre a tranquilidade e a segurança desse espaço.

Conforme o desenvolvimento econômico, a infraestrutura, os aparatos tecnológicos e a comunicação, o transporte público e a educação vão alcançando o campo, as diferenças entre os tipos de delito praticados em zonas urbanas e rurais tendem a desaparecer, enfraquecendo as fronteiras imaginárias que distanciavam esses espaços. Tempos atrás, a violência urbana era concebida como uma prática mais elaborada que exigia um desempenho intelectual maior do indivíduo, diferente dos crimes cometidos no campo onde se utilizavam meios cruéis na prática delitiva que geralmente era exercida contra a pessoa (FELIX, 2002). No mesmo sentido, em décadas passadas a incidência de determinados crimes geralmente estava relacionada com suas espacialidades, isto é, as cidades apresentavam tipos característicos de crime, como sequestro, roubo, roubo à mão armada, estrupo e tráfico de drogas. Já os crimes de sangue (como vingança) se relacionavam com o campo. É notável pelos meios de comunicação que este cenário têm se modificado e as fronteiras criminológicas, assim como as fronteiras espaciais, já não são tão visíveis (BEATO, 1998).

Entre as diversas práticas criminais que vêm sendo apontadas pela mídia como mais frequentes no campo, temos os crimes contra o patrimônio (contra a propriedade): furto e roubo de gado e maquinários agrícolas, e dano patrimonial. Há também os crimes contra a pessoa (crimes violentos, contra a vida): homicídio tentado, homicídio consumado, lesões corporais e estrupo. O uso e tráfico de drogas também ganham destaque, principalmente pelo envolvimento da juventude rural nesses delitos.

Após a observação das notícias foi possível identificar cinco categorias de informações sobre a criminalidade no campo: os "tipos criminais praticados"; "quantidade de ocorrências reincidentes em uma mesma propriedade"; "os principais alvos das Unidades da Federação e estimativa de prejuízo para cada Estado"; "estratégias de segurança adotadas para reduzir a criminalidade" e se "a criminalidade contribui e/ou é influenciada pelo esvaziamento do campo".

A observação das reportagens permitiu esboçar um panorama geral da criminalidade no campo em todas as regiões do Brasil (figura 2), onde se destacam a região sul e sudeste, consideradas as mais ricas do país em termos econômicos, que foram focalizadas por pouco mais da metade das reportagens analisadas. 
Figura 2. Ocorrências no campo por regiões brasileiras. Figure 2 -Occurrences in the countryside by Brazilian Region

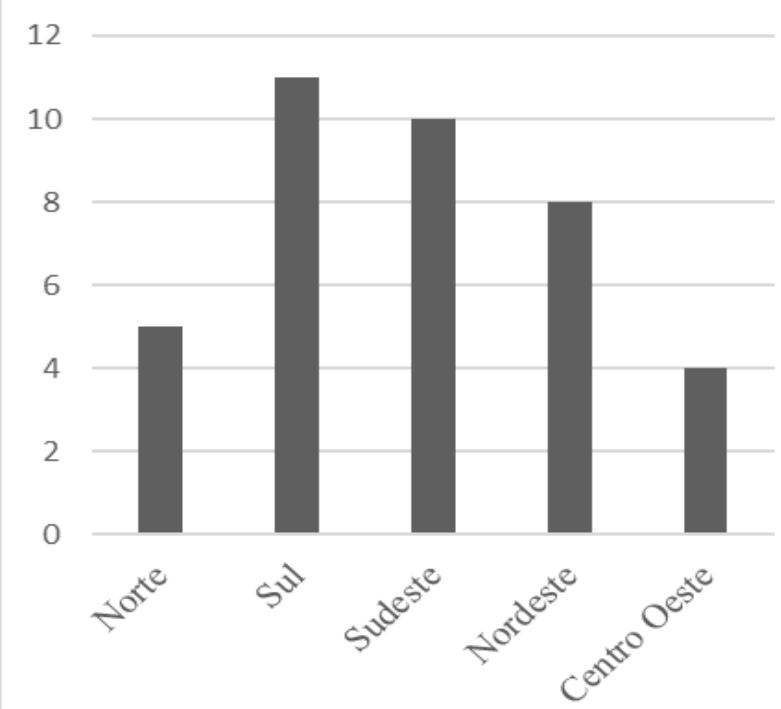

Fonte: elaborado pelos autores com base nas informações das reportagens selecionadas -2018 .

É importante ressaltar que há uma quantidade grande de notícias que narram crimes cometidos em zonas urbanas mas cujas evidências são deixadas no campo, como por exemplo, roubo e furto de veículos, que são abandonados na zona rural e casos de homicídios que também são cometidos nas cidades e o abandono dos corpos é feito no meio rural. Essas reportagens abordam o campo de forma indireta, mais como zona de descarte de provas e indícios. Tais notícias, portanto, também não deixam de veicular uma mensagem negativa sobre as facilidades encontradas para o crime no meio rural.

Dentre os crimes apresentados nas reportagens destacam-se o roubo tentado e consumado, o furto, abigeato, homicídio, latrocínio e o crime de trabalho em condição análoga a de escravo (TABELA 1) ${ }^{6}$. As regiões Sul, Sudeste e Centro Oeste apresentam um maior número de ocorrências nas práticas de crime contra o patrimônio, ou seja, o abigeato, furto, roubo tentado e consumado, principalmente pelo fato de concentrarem um grande

\footnotetext{
${ }^{6} \mathrm{O}$ número de crimes registrados diverge do número de reportagens devido ao fato de que as reportagens selecionadas retratam mais de uma ocorrência.
}

número de pecuaristas e agricultores. As regiões Norte e Nordeste se destacam nos crimes contra a pessoa (homicídio e o latrocínio) ${ }^{7}$.

Tabela 1. Crimes registrados nas reportagens

Table 1 - Crimes documented in the TV news stories

\begin{tabular}{|l|c|}
\hline Crime & Quantidade \\
\hline Abigeato & 13 \\
\hline Homicídio & 11 \\
\hline Roubo & 17 \\
\hline Roubo Tentado & 1 \\
\hline Furto & 6 \\
\hline Condição análoga de escravo & 1 \\
\hline TOTAL & $\mathbf{4 9}$ \\
\hline
\end{tabular}

Fonte: elaborado pelos autores com base nas informações das reportagens selecionadas -2018

Contrapondo os dados da tabela acima com os disponibilizados pela CNA, percebese que, apesar do pequeno número de reportagens televisionadas, existe uma correlação entre as ambas informações. O furto, nos dados do CNA, apresenta uma maior percentagem corroborando com os dados da tabela 1 . Ressalta-se que a mídia apresenta o furto subdivido em duas categorias, a de furto em stricto sensu e a de abigeato que é o furto e abatimento de animais.

Os telejornais são um território simbólico e por meio de reportagens possuem a capacidade de estimular opiniões. As grandes cidades brasileiras já figuram no imaginário da população como um lugar violento. Partindo do pressuposto de que os aspectos que fogem

\footnotetext{
${ }^{7}$ No título II da Lei 2.848, de 7 de dezembro de 1940 do Código Penal Brasileiro estão previstos os crimes contra o patrimônio, que em sua maioria aplica-se a esta pesquisa. O furto está tipificado no artigo 155 da referida lei e é conceituado como: "Subtrair para si ou para outrem, coisa alheia móvel". O artigo 157 conceitua o crime de roubo como "Subtrair coisa móvel alheia, para si ou para outrem, mediante grave ameaça ou violência a pessoa, ou depois de havê-la, por qualquer meio, reduzido à impossibilidade de resistência." (BRASIL, 1940). Já o abigeato é tipificado pela Lei 13.330/16que “altera o Decreto-Lei № 2.848, de 7 de dezembro de 1940 (Código Penal), para tipificar, de forma mais gravosa, os crimes de furto e de receptação de semovente domesticável de produção, ainda que abatido ou dividido em partes." (BRASIL,2016).
}

https://periodicos.unifap.br/index.php/estacao Macapá, v. 9, n. 1, p. 133-146, Jan./Mar. 2019 
aos cotidianos da população geram audiência, a mídia tende a se concentrar em torno deles (COGO, 2012). Logo, cabe expor que o baixo número de reportagens televisionadas está intimamente relacionado com a necessidade de captar espectadores.

A reportagem "Criminalidade no campo gera prejuízos milionários”, veiculada no dia 10 de outubro de 2017 pelo programa Jornal da Band, do grupo Bandeirantes, destaca a importância de confrontar o imaginário social que se tinha sobre o campo, conforme pode ser observado na chamada da reportagem:

Viver em paz. no campo é coisa do passado. Moradores de áreas rurais cada vez. mais sofrem com a violência crescente. Fazendeiros denunciam roubos, ameaças e prejuízos milionários (Apresentador, Jornal da Band, 10/10/2017).

Mas as reportagens não se limitam a divulgar apenas o aumento da criminalidade contra os grandes fazendeiros; ao contrário, as narrativas e imagens mostram que pequenos proprietários, trabalhadores rurais e pessoas idosas também passaram a integrar o conjunto de vítimas, o que contribui para criar a representação de uma criminalidade generalizada. Assim, buscando mostrar a violência que os aposentados rurais vêm sofrendo, o programa "Bom Dia Piauí", vinculado à Rede Globo de Televisão, publicou no dia 15 de fevereiro de 2018 a reportagem "Mulher é assassinada dentro de casa na zona rural de Barras” com a seguinte narrativa:

Uma idosa de 65 anos foi morta a facada dentro de casa durante uma tentativa de assalto na zona rural do $\mathrm{Mu}$ nicípio de Barras e a polícia faz, busca para capturar o suspeito que fugin sem conseguir realizar o assalto (Apresentador, Bom Dia Piauí, 15/02/2018).

O agricultor familiar, que geralmente não faz uso de maquinário agrícola de alto valor econômico, tem sido vítima também da ação de criminosos. A reportagem "Polícia procura criminosos que invadiram propriedades rurais em Estrela do Sul e Grupiara-MG" do programa MGTV $1^{\text {a }}$ edição, apresentado no dia 05 de Março de 2018, buscou apresentar a "onda de criminalidade" pela qual passam duas cidades do interior de Minas Gerais e nela se pode observar um consenso nos discursos de diferentes atores sociais entrevistados:

A policia procura pelos bandidos que invadiram a propriedade rural em Estrela do Sul, no alto Paranaíba. O local foi roubado e o produtor rural foi levado como refém. Os moradores relataram que nos últimos 2 dias, 7 propriedades da zona rural de Grupiara e Estrela do Sul foram alvos de criminosos (Apresentador, MGTV $1^{a}$ edição, 05/03/2018).

Tudo indica que eles vieram pelo mato. Eles chegaram como se fosse uma visita normal, né, sem nenhum tipo de suspeita. Já foi anunciado o assalto, perguntando onde estava a carteira para ver se tinha dinheiro. Feito isto, eles pegaram o carro e levaram o dono desta casa como refém (Parente da vítima, MGTV $1^{a}$ edição, 05/03/2018).

Os dois autores [do crime] que estavam com a vitima conheciam bem a região. Então eles foram por estradas vicinais até desconhecidas por moradores da região. Então eles conbeciam bem a região(Policial Militar, MGTV $1^{a}$ edição, 05/03/2018).

Eu me sinto humilhado, né? A gente trabalha, paga os impostos (...). Os bandidos estão armados, nós não podemos ter uma arma em casa. Então eles chegam e fazem da gente o que quiser, batem e levam as coisas da gente (Produtor rural, MGTV $1^{a}$ edição, 05/03/2018).

Nesta região que inclui este distrito vivem cerca de trezentas pessoas. A sensação de tranquilidade é coisa do passado (Apresentador, MGTV $1^{a}$ edição, 05/03/2018)

Eles estão aterrorizando com arma pesada. Ninguém está tendo mais sossego (Moradora, MGTV $1^{a}$ edição, 05/03/2018).

A tranquilidade do distrito acaba aqui, da porteira para dentro o produtor rural tem sofrido com a violência. Os roubos a fazenda cresceram 3\%, comparando os dez. primeiros meses de 2017 com o mesmo periodo de 2016. Por onde os bandidos passam levam tudo, deixam muita 
bagunça e insegurança. Os moradores cobram policiamento e não descartam deixar o campo (Apresentador, MGTV 1ª edição, 05/03/2018).

A mesma cena se repete em outras regiões do país incluindo as mesmas categorias de vítimas, os mesmos tipos de ações criminais e os alvos dos criminosos. Tal semelhança pode ser observada na reportagem "Crimes na zona rural preocupam moradores de Cacoal" exibida no dia 21 de janeiro de 2017 pelo Jornal de Rondônia:

Em Cacoal, os crimes na Zona Rural têm tirado o sossego. As polícias civil e militar investigam os assaltos recentes na região (Apresentador, Jornal de Rondônia, 21/01/2017).

Nas últimas semanas, toda essa tranquilidade da zona rural de Cacoal vem sendo ameaçada pela criminalidade. Os moradores têm sido alvo de assaltantes, que aproveitam o isolamento e a falta de policiais no local. Senhor João, de 78 anos, que mora na linha onze e já teve a casa roubada, conta que morar na zona rural não tem sido mais sinônimo de tranquilidade (Repórter, Jornal de Rondônia, 21/01/2017).

Já levaram roupa do meu guarda roupa, só não levaram a televisão porque ela é meio pesadinha, mais o resto tiveram tempo (Sr. João - Morador, Jornal de Rondônia, $21 / 01 / 2017)$.

Em uma semana a policia registrou o roubo de duas caminhonetes no município, uma delas era do Sr. Luis Rezende. Ele disse que foi rendido pelos assaltantes quando retornava da igreja (Repórter, Jornal de Rondônia, 21/01/2017).

A polícia conseguiu recuperar os veículos, más nenbum dos suspeitos foi preso. A polícia acredita que os roubos ocorridos nas zona rural possam ter sido praticados por uma quadrilha especializada, isso porque nos dois assaltos a ação dos criminosos foi a mesma. Eles chegaram encapuzados e armados, renderam e amarraram as vítimas (Repórter, Jornal de Rondônia, 21 /01/2017).

Nós acreditamos que é um bando especializado que já tem uma destinação certa de onde e pra quem passar esses objetos furtados (Comandante da polícia, Jornal de Rondônia, 21/01/2017).
A comunidade da zona rural espera que com a prisão dos suspeitos a sensação de insegurança dê lugar à tranquilidade (Repórter, Jornal de Rondônia, 21/01/2017).

$\mathrm{Na}$ categoria de análise "Tipos criminais praticados no campo", o roubo e o furto de gado destacam-se como principais assuntos noticiados pelas reportagens, seguindo a estimativa realizada pelo Observatório da Criminalidade no Campo (CNA, 2017), que constatou cerca de $82 \%$ destes crimes no período de janeiro a julho de 2017. Vale ressaltar que nas representações dos produtores rurais roubo e furto acabam configurando um mesmo delito. Para distinguir o tipo criminal a partir das falas nas reportagens, tomou-se como critério distinguir aquelas que dissertavam sobre o emprego de grave ameaça ou violência que coloca a vida de outrem em perigo e aquelas que relavam somente a subtração dos bens. Neste sentido, foi possível perceber que o furto e o abigeato são os mais presentes no campo.

O abigeato (furto, e receptação de animal, mesmo que divididos em partes)conta com atuação de quadrilhas especializadas nesses delitos, contribuindo para o mercado clandestino nacional e internacional de carnes, intensificando sua atuação em épocas festivas como Natal e Ano Novo, por ser um período onde há maior consumo de carne. Frequentemente essas quadrilhas procuram propriedades com embarcadores ${ }^{8}$ nos pastos, que facilitam a acomodação dos animais nos caminhões, e tornam a atuação dos criminosos mais rápida.

Em menor quantidade nas reportagens aparece a prática do homicídio, o que também não difere dos dados do Observatório da Criminalidade no Campo. O homicídio é caracterizado como crime de motivo torpe (fútil) e que ocorre na maioria das vezes por de-

\footnotetext{
${ }^{8}$ Objeto situado entre o curral e o pasto utilizado para embarcar o gado no caminhão.
}

https://periodicos.unifap.br/index.php/estacao 
sentendimentos em bares entre pessoas próximas ou até mesmo com algum grau de parentesco. As armas utilizadas nesses delitos geralmente fazem parte do quadro de ferramentas agrícolas e por isso apresentam níveis mais cruéis de execução, ocasionando um grande derramamento de sangue (BEATO, 1998; FELIX 2002). Vale ressaltar que esse tipo de crime não migrou para o rural como outros tipos de delitos. Ele já tem sua origem histórica nesse espaço (FRANCO, 1983). Há ainda homicídios cujas vítimas são executadas por resistirem à entrega de objetos no momento da atuação de criminosos, tal como acontece nos contextos urbanos.

$\mathrm{Na}$ categoria "Número de reincidência criminal em uma mesma propriedade" observou-se que os praticantes de furto e abigeato chegam a ser representados pelos produtores rurais como "clientes" devido ao grande número de vezes que "visitam" a mesma propriedade. Esta reincidência ocorre pela facilidade que o campo proporciona para os criminosos fugirem e terem várias alternativas de rotas de fuga. As imagens que circulam nessas reportagens mostram marcas de pneus de caminhão pelo solo onde ocorreu a prática criminal.

Com relação às "Estimativas de prejuízo e as principais Unidades da Federação", observou-se que o Estado do Rio Grande do Sul destaca-se pelo maior prejuízo contabilizado no ano de 2017, somando um total de $70 \mathrm{mi}$ lhões de reais, seguido pelo Distrito Federal, 300 mil, e São Paulo com 200 mil reais. Os Estados de Goiás e Pernambuco, embora fossem noticiados, não tiveram os valores roubados divulgados (Tabela 2).
Tabela 2. Estimativas de prejuízo por furto nas Unidades da Federação em áreas rurais brasileiras.

Table 2 - Estimated financial losses by theft for each Federation Unit in rural brazilian space

\begin{tabular}{|l|l|}
\hline UF & VALOR (R\$) \\
\hline RS & 70 milhões \\
\hline DF & 300 mil \\
\hline SP & Mais de 200 mil \\
\hline MG & 30 mil \\
\hline PE & Não divulgado \\
\hline GO & Não divulgado \\
\hline
\end{tabular}

Fonte: elaborado pelos autores com base nas informações das reportagens selecionadas -2018

Essas estimativas são contabilizadas geralmente levando-se em consideração o número de cabeças de animais ou maquinários e suplementos agrícolas que foram objetos de furtos. Para calcular o valor do prejuízo são analisados a raça do animal, o peso, a quantidade de produção de leite e seu aspecto físico. $\mathrm{O}$ mesmo ocorre para maquinários e suplementos agrícolas, que passam a ter seu prejuízo contabilizado pela marca, função e estimativa do valor de compra.

Esses dados foram obtidos a partir do discurso e das narrativas dos entrevistados, nas reportagens onde foram selecionados produtores rurais, presidentes de sindicatos rurais e trabalhadores, buscando demonstrar a situação de cada Estado/Região.

As "Estratégias de segurança adotadas no campo para reduzir a criminalidade" constituem a quarta categoria de análise deste trabalho e têm ganhado relevância nos veículos de comunicação devido à quantidade de técnicas e mecanismos criados. A tecnologia que chega ao campo impulsionada pelo agronegócio também vem trazendo novas estratégias de segurança desenvolvidas pelo setor industrial. Aparelhos como câmera de segurança, aplicativos de celulares, sistemas de sirenes, geoprocessamento das propriedades, placas de aviso, treinamento de cães, cartilhas de orientação e prevenção são alguns dos mecanismos empregados para combater essa insegurança.

Cabe ressaltar que o investimento nesses mecanismos, na grande maioria das vezes, não aumenta a sensação de proteção: 
A gente tenta fechar a propriedade, cerca, portão eletrônico, tem que usar das mais variadas formas de proteção, só que como as fažendas são grandes, fica difícil você tentar proteger na sua totalidade (Carmos Triacca produtor rural, Criminalidade no campo gera prejuizos milionários, Jornal da Band, 10/10/2017).

Outras alternativas também têm sido empregadas, como a criação da patrulha rural, órgão da polícia militar destinado a atender ocorrências no campo, delegacias especializadas em crimes rurais e empresas de segurança privada que prestam consultorias para sindicatos de produtores rurais. Mesmo assim o problema está longe de acabar:

A patrulha rural é acionada para mais uma ocorrência, mas quando os policiais chegam à fazenda os ladrões já levaram o gado (Repórter, Criminalidade no campo gera prejuízos milionários, Jornal da Band, 10/10/2017).

Para indicar se "A criminalidade contribui e/ou é influenciada pelo esvaziamento do campo", a mídia representa o contexto rural utilizando os recursos de imagens e narrativas de produtores atribuindo grande comoção ao tema. Nos crimes de furto e roubo, enquanto as narrativas são transmitidas, circulam imagens de propriedades abandonadas, "casinhas" bem simples, em estado de degradação. Também são focalizados os olhares de tristeza dos pequenos agricultores que se despedem da propriedade e migram para os centros urbanos. Imagens de gado nos pastos também são utilizadas para demonstraras perdas que as propriedades vêm sofrendo. Nessa categoria foi possível observar que o aumento da criminalidade afeta de forma diferenciada grandes e pequenos proprietários. Os fazendeiros são focalizados quando o tema é o uso de tecnologias sofisticadas e caras de proteção; os pequenos proprietários, ao contrário, embora sejam alvos da mesma violência, são representados como totalmente impotentes e a quem só resta a alternativa de migração na já citada reportagem sobre a criminalidade.
Em uma cidade do interior de Minas Gerais, um morador entrevistado questiona:

Como é que você fica no campo desse jeito? Sem segurança, sem nada e os bandidos atacando Morador, MGTV $1^{a}$ edição, 05/03/2018).

Quando os assuntos transmitidos são crimes contra a pessoa, as imagens veiculadas geralmente apresentam os instrumentos utilizados manchados de sangue. $\mathrm{Na}$ maioria das vezes, tais instrumentos são ferramentas utilizadas para o trabalho no campo, como enxadas, foices, machados, facões ou facas, o que caracteriza o meio cruel empregado na ação criminal, diferenciando o "modus operandi" dos crimes urbanos (BEATO, 1998; FELIX, 2002).Esses crimes ainda são representados como tipicamente rurais, pois geralmente envolvem membros de uma mesma comunidade, que podem ser até "compadres e amigos", mas que por motivo fútil passam a se desentender e, num processo de autoafirmação e valentia, acabam se matando (FRANCO, 1983).

Buscando elevar o índice de audiência, principalmente quando o tema transmitido é violência, os veículos de comunicação de massa utilizam vários mecanismos para enaltecer o assunto transmitido. Mesmo utilizando recursos narrativos e imagéticos de espetacularização, tais veículos ainda constituem fontes importantes para o estudo das representações sociais na medida em que põem em circulação ideias, valores morais, julgamentos e avaliações sobre a realidade e sobre novos fenômenos e novas configurações da sociedade contemporânea.

\section{Considerações finais}

Os recentes índices estatísticos sobre a criminalidade no campo contribuem para o entendimento de que o meio rural está passando por um processo de transformação. As imagens e discursos que forneciam a base

https://periodicos.unifap.br/index.php/estacao Macapá, v. 9, n. 1, p. 133-146, Jan./Mar. 2019 
simbólica para um imaginário sobre o rural como local de tranquilidade e de bem estar passaram a ser questionadas e amplificadas pelos veículos de comunicação de massa, criando um novo consenso coletivo.

A atuação da mídia nesse processo é fundamental, pois busca dar visibilidade ao problema social da criminalidade que chega ao campo nos últimos anos, alcançando uma grande proporção de público. Apesar de haver um campo de disputa por audiência, verificou-se que uma das estratégias utilizadas pelas redes de TV foi a de mesclar e aproximar narrativas e imagens sobre a criminalidade em contextos locais, regionais e nacional. Essa estratégia contribui para criar uma representação da criminalidade não como fato isolado, mas como fenômeno generalizado nos espaços rurais.

Outro consenso verificado nas reportagens refere-se aos impactos e às reações dos diferentes atores sociais frente ao aumento da criminalidade. Para os pequenos proprietários, trabalhadores e moradores rurais de baixa renda, a ausência de políticas de segurança pública e o aumento da criminalidade resultam na dificuldade ou mesmo impossibilidade de permanência no campo e a migração urbana é apontada como alternativa. Já os grandes proprietários, que podem enfrentar a ausência das ações do Estado e arcar financeiramente com a própria segurança, têm a sua disposição um mercado em franco crescimento de equipamentos modernos e serviços de proteção. As reportagens analisadas utilizam imagens que mostram inclusive as modificações de arquitetura das grandes propriedades, necessárias para adaptar as instalações dos sistemas tecnológicos de segurança.

Contrariando as representações sociais que se tinha do campo há décadas atrás, caracterizado como espaço tranquilo e de bem estar que proporcionava uma boa qualidade de vida e segurança, o rural passa agora a fazer parte do cenário da criminalidade e violência nacio- nal e a compor as estatísticas de segurança púbica. A observação das reportagens sobre o aumento da criminalidade, nas quais se mesclam dados estatísticos e percepções de diferentes atores sociais, permite apontar a criação embrionária de um novo conjunto simbólico, que une o fato à sua representação, alterando o signo de positividade atribuído ao rural.

\section{Referências}

BARDIN, L. Análise de conteúdo. Tradução de Luís Antero Reto e Augusto pinheiro. $3^{\mathrm{a}}$. ed. São Paulo: Edições 70, 2001.281 p.

BEATO, C.C. F. Determinantes da criminalidade em Minas Gerais. Revista Brasileira de Ciências Sociais. vol. $13 \mathrm{~N}^{\circ}$ 37. 1998. https://doi.org/10.1590/S0102-69091998000200004 BRASIL. Decreto lei no 2.848, de 7 de dezembro de 1940. Código Penal Brasileiro. Diário Oficial da República Federativa do Brasil, Brasília, 7 de dezembro de 1940.

BRASIL. Decreto lei no 13.330, de 2 de agosto de 2016. Altera o Decreto-Lei no 2.848, de 7 de dezembro de 1940 (Código Penal). Diário Oficial da República Federativa do Brasil, Brasília, 2 de agosto de 2016.

CARNEIRO, M. J. Juventude e novas mentalidades no cenário rural. In: CARNEIRO, M. J.; CASTRO, E. G. Juventude Rural em perspectiva. Rio de Janeiro, Mauad X, 2007. p.53-66.

CNA. CONFEDERAÇÃO DA AGRICULTURA E PECUÁRIA DO BRASIL. Observatório da Criminalidade no Campo. 2017. Disponível em: <www.cnabrasil.org.br>. Acesso em: 17 out. 2017.

COGO, D. Latino-americanos em diáspora: usos de mídias e cidadania das migrações transnacionais. Rio de Janeiro: Tríbia, 2012. https://doi.org/10.16921/chasqui.v0i123.62

DINIZ, A. M. A. Migração, desorganização social e violência urbana em Minas Gerais. R. RA'E GA, Curitiba, n. 9, p. 9-23, 2005. https://doi.org/10.5380/raega.v9i0.3443

FELIX. S. A. Geografia do crime: interdisMacapá, v. 9, n. 1, p. 133-146, Jan./Mar. 2019 
ciplinaridade e relevâncias. Marília: Unesp Publicações, 2002, 149 p.

FERNANDES, Francisco Assis Martins. O papel da mídia na defesa do meio ambiente. Taubaté: Revista Ciências Humanas UNITAU, v. 7, $\mathrm{n}^{\circ}$ 2, 2001.

FORUM BRASILEIRO DE SEGURANÇA PÚBLICA. Anuário Brasileiro de Segurança Pública. 11. ed., 2017.

FRANCO, M. S. de C. Homens livres na ordem escravocrata. São Paulo: Kairós Livraria Editora LTDA, 1983, 226p.

GIL, A. C. Métodos e técnicas de pesquisa social. São Paulo: Atlas, 2008. 200 p.

GLOBO. História - Grupo Globo. 2013. Disponível em: <http://historiagrupoglobo. globo.com $/ \mathrm{hgg} /$ index.htm> Acesso em: 06 de nov. de 2017.

GRUPO BANDEIRANTES. História. 2017. Disponível em: <http://www.grupobandei rantes.com.br/> - Portal do maior grupo multimídia brasileiro. Acesso em: 06 de nov. de 2017.

JODELET, D. Representações sociais: um domínio em expansão: In: JODELET. D. (org) As representações sociais. Rio de Janeiro, Ed. UERJ, 2001. p.18-66.

MENASCHE, R. Os grãos da discórdia e o trabalho da mídia. Opinião Pública [online]. 2005, vol. 11, n.1, pp. 169-191. https://doi.org/10.1590/S0104-62762005000100007

PESAVENTO, S. Em busca de outra história: imaginando o imaginário. Revista Brasileira de História, São Paulo, v. 15, n. 29, 1995.

PORTO, M. S. G. Mídia, segurança pública e representações sociais. Tempo Social: Revista de sociologia da USP, São Paulo, v. 2, n. 21, p.211-233, 2009. https://doi.org/10.1590/S010320702009000200010

RAUPP, F. M; BEUREN, I. M. Metodologia da pesquisa aplicável às ciências sociais. v. 3, p. 76-97, 2003. Disponível em: <http:// www.geocities.ws/cienciascontabeisfecea/esta gio/Cap_3_Como_Elaborar.pdf $>$ Acesso em: 21 de set de 2017.
SÊGA, R. A. O conceito de representação social nas obras de Denise Jodelet e Serge Moscovici. Anos 90. Porto Alegre, 2000. https://doi.org/10.22456/1983-201X.6719

SILVA M. M. C; DOULA, S. M. Representações sociais sobre a Aids entre jovens rurais e urbanos de Minas Gerais. Semina: Ciências Sociais e Humanas, Londrina, v. 35, n. 2, p. 77-90. 2014.

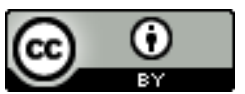

License information: This is an openaccess article distributed under the terms of the Creative Commons Attribution License, which permits unrestricted use, distribution, and reproduction in any medium, provided the original work is properly cited.

Artigo recebido em 26 de maio de 2018.

Avaliado em 26 de setembro de 2019.

Aceito em 30 de setembro de 2019.

Publicado em 02 de outubro de 2019.

Como citar este artigo (ABNT):

VIEIRA, João Paulo Louzada; DOULA, Sheila Maria. "Viver em paz no campo é coisa do passado": deslocamento espacial de ações criminosas e a ressignificação do rural brasileiro. Estação Científica (UNIFAP), Macapá, v. 9, n. 1, p. 133-146, jan./mar. 2019. 